\title{
Dos Paradigmas Hermenéuticos del Pensamiento Político de Tomás de Aquino: sus VirTudes, LIMITACIONES Y VIRTUALIDADES ${ }^{1}$
}

\author{
Santiago Argüello ${ }^{2}$
}

\begin{abstract}
RESUMEN: El presente trabajo examina dos de los principales modelos de exposición del pensamiento político de Tomás de Aquino vigentes en el siglo XX. Uno, en cuya representación se ha escogido la obra de Eschmann, mira a la relación de la obra del Aquinate con sus predecesores; el otro, adecuadamente representado por Ullmann, mira a la relación de dicha obra con el pensamiento que se proyecta a partir de él hacia la Modernidad. Al determinar tanto las virtudes cuanto limitaciones propias de estos modelos hermenéuticos, se hace posible advertir las virtualidades presentes en los mismos, abriendo nuevos caminos de investigación que superen la tensión concebida entre el poder eclesiástico y el civil, así como el temor por reanimar un concepto que, si bien embrionario en la obra del autor medieval, es imprescindible para comprender cabalmente su reactivación del republicanismo aristotélico. Tal es el concepto de nación.
\end{abstract}

PALABRAS CLAVES: Tomás de Aquino. Pensamiento político medieval. Iglesia. Estado. Nación.

\section{INTRODUCCIÓN}

La filosofía política de Tomás de Aquino ha sido objeto de interpretaciones no sólo variadas sino a veces incluso divergentes; y todavía lo sigue siendo. Lo interesante al respecto es que en la discusión en torno a ella no sólo han intervenido adherentes a ella, ni tampoco exclusivamente conocedores de la filosofía tomista en general, sino también un amplio espectro de expertos en materias diversas: politólogos, juristas, historiadores, medievalistas, filósofos, teólogos, expertos en eclesiología, historiadores del arte, etc.

Si la cuestión central del pensamiento político medieval fue la de la relación entre el poder espiritual y el temporal ${ }^{3}$, podría decirse que el gran tema del pensamiento político moderno es el de la configuración de los pueblos como

\footnotetext{
${ }^{1}$ http://dx.doi.org/10.1590/S0101-31732016000200003

${ }^{2}$ Ph. D., L.M.S. CONICET - Universidad de Mendoza. Argentina. E-mail: yagoarg@yahoo.com.ar

${ }^{3}$ En efecto, todas las teorías políticas medievales "[...] coinciden en el común intento de resolver, teóricamente, un problema fáctico: el conflicto entre el poder espiritual y temporal." (BERTELLONI, 2010, p.18).
} 
Estados nacionales. El pensamiento de Tomás de Aquino ha sido objeto no sólo de interpretación en lo tocante a la primera de esas cuestiones, sino también a la segunda. En esto también se nota, por lo demás, la originalidad tomística respecto de la tradición medieval. A la vista de las dos cuestiones señaladas, mi intención en el trabajo presente es exhibir dos representantes cualificados de investigación en las teorías políticas del Aquinate a modo, precisamente, de paradigmas hermenéuticos. Y al tiempo de exhibirlos, discutir con ellos. Así, si la interpretación de Ignatius Eschmann es paradigma de la tensión Estado/ Iglesia, la de Walter Ullmann lo es de la fusión repúblicalnación. Expresado de forma sintética, la lógica implicada en ambas hermenéuticas es postular la necesidad de una opción unilateral o absoluta entre los dos conceptos en juego, sea en forma de disyuntiva, sea en forma de confusión entre ambos.

De modo introductorio y señalando las limitaciones inherentes a los modos usuales de interpretar el pensamiento político de Tomás, cabe decir que, o bien se opera una reducción de dicho pensamiento al agustinismo político, o bien, en el mejor de los casos, se supone un debate dialéctico interno a la obra de Tomás entre dicho agustinismo y el republicanismo aristotélico. Así, en su interpretación del De regno, Eschmann identifica la postura de ese opúsculo con una postura de tipo agustinista o teocrática, contraponiéndola a la postura republicana de otras obras de Tomás. La erudita defensa del republicanismo de Tomás de Aquino llevada a cabo por este dominico alemán, se realiza al precio de erradicar el De regno de su pensamiento genuino, considerándolo como un elemento extrańo en el corpus thomisticum. De la interpretación de Eschmann, me interesa destacar precisamente ese punto: la consideración del De regno como ejemplo de agustinismo político $^{4}$; apreciación que me parece desacertada.

En lo que se refiere al establecimiento de cierta pugna dialéctica entre agustinismo y aristotelismo en el seno del pensamiento político de Tomás de Aquino, además del mismo Eschmann, que era tomista, hay otros intérpretes que, sin serlo, igualmente concluyen en la suposición de dicha dialéctica. Este, por ejemplo, es el caso de Ullmann. Como argumentaré, la falsedad de esta suposición reside en la consideración de los términos agustinismo y aristotelismo como existentes en un mismo plano o nivel de significación, imaginando una incompatibilidad mutua a causa de una supuesta competencia mutua.

\footnotetext{
${ }^{4}$ Dos son los trabajos más importantes al respecto: Eschmann $(1958,1979)$. Respecto del segundo de ellos, en su prefacio a la ed. leon. del De regno, H.-F. Dondaine (1979, p. 422, nota n. 8) apuntaba en nota lo siguiente: "L'introduction et les notes d'Eschmann sont documentées et pénétrantes". También pueden consultarse Eschmann (1946, 1947, 1956).
} 
En relación al supuesto teocratismo de la obra de Tomás de Aquino en su conjunto, puede hacerse notar que, aunque ya casi no hay apologetas de una postura monárquico-absolutista presente en esa obra (o, si los hay, no cuentan con realce hermenéutico) $)^{5}$, sí hay intérpretes de renombre que siguen denunciado la existencia de dicha postura en Tomás, pero precisamente para atacarla. Tal es el caso de Arendt (2003, p. 37-95, es decir, el entero cap. II) y Habermas (1987, p. 54-57), para quienes una postura de tipo republicana, radicada en los griegos y los romanos antiimperialistas, no sólo estaría lejos de haber encontrado lugar en la obra del autor medieval, sino que incluso se encuentra en una vereda totalmente opuesta a ella. Esta apreciación tampoco me parece adecuada.

A mi modo de ver, el pensamiento político de Tomás, antes que reducirse al agustinismo político, o plantear una pugna dialéctica entre agustinismo y aristotelismo, presenta, particularmente en el De regno, una pluriforme y dinámica filosofía política que, recibiendo la influencia de distintas tradiciones, sabe conjugarlas según diversos planos, obteniendo así por resultado un sistema filosófico-político rico y pluridimensional.

Ahora bien, incluso en las interpretaciones de la filosofía política de Tomás de Aquino elaboradas por Eschmann o Ullmann, junto a sus inherentes limitaciones, es posible descubrir ciertas verdades; y en algunos casos, no sólo verdades puntuales, sino más bien estructurales, las cuales pueden suscitar hasta todo un programa de investigación. No pretendo, en este sentido, escatimar el hecho de que la misma interpretación presente se haya originado de algún modo en discusión con aquellas.

\section{El paradigma de la tensión Estado/IgLESIA}

Asumiendo las indicaciones del editor leonino del De regno, HyacintheFrançois Dondaine (1979), el carácter precario y circunstancial de dicho opúsculo, es un hecho cierto e innegable. Sin introducirnos aquí en los pormenores de la cuestión, no parece haber dificultad entre los estudiosos en asentir al hecho de que el De regno no sólo ha sido una obra en cierto modo retaceada, o al menos abreviada -lo que ha dado por resultado una edición original más bien precaria-, sino que su elaboración estuvo estrechamente

\footnotetext{
${ }^{5}$ Como se revela por los trabajos de Blythe (1986, p. 547, n.1) e Imbach (1994), los últimos intérpretes en defender con cierto predicamento a Tomás de Aquino como un monárquico absoluto, sea en el ámbito anglosajón, sea en el francés, son autores que no pasan de la década de 1930.
} 
condicionada por circunstancias históricas. Por no tener suficientemente en claro este último punto, y considerarla, pues, como obra de auténtico calado teórico-político, Eschmann desató toda una controversia en torno a una supuesta natural competencia o contradicción entre una postura republicana y una teocrática en el seno del pensamiento de Tomás de Aquino. Lo notable del caso es que, por no tomar en consideración las cuestiones de orden contextual en torno al De regno, algunos estudios sobre este opúsculo tienden a caer en el mismo error básico en que caía Eschmann. No es raro, así, encontrar toda una serie de deducciones teórico-políticas atribuidas al pensamiento político más relevante de Tomás Aquino, precisamente a partir del De regno ${ }^{6}$. De esta forma, como ya se figurara Eschmann, el De regno se alinearía, o bien al teocratismo del agustinismo político medieval ${ }^{7}, \mathrm{o}-$ según interpretación más reciente (HABERMAS, 1987, p. 54-57; BERTELLONI, 2009, p. 66) -, al distinguir lo social de lo político y abogando por la supremacía de lo primero sobre lo segundo, el De regno se insinuaría ya precursor de Hobbes.

Desde luego, no pretendo alegar que su condición circunstancial le quite al De regno originalidad teórica (TURSI, 2003, p. 53-54). Con todo, el peso de su originalidad es mucho menos grave de lo que se supone. $\mathrm{O}$, mejor dicho, lo que habría que revisar, en todo caso, es el papel que el Aquinate mismo otorga a la originalidad teórica de una obra de esa índole, cercana a los espejos de príncipes, en los cuales la teoría parece estar al entero servicio de la práctica. Por otra parte, algunos (pocos) estudios recientes sobre el De regno han sabido identificar distintas líneas teóricas presentes en él, y de las que él dependería ${ }^{8}$. De esta forma, no se trataría de una simple propuesta hierocrática, sino de un entramado de diversas tradiciones de pensamiento social y político, entre las cuales también es posible, ciertamente, descubrir cierto orden de relaciones mutuas. En efecto, no por el hecho de que diversas tradiciones puedan convivir pacíficamente, sin colisionar las unas con las otras, habrán de encontrarse las mismas en plano de igualdad axiológica.

Desde luego, la importancia de Eschmann respecto de la interpretación del De regno reside en haber sido la primera dotada de claras intenciones concluyentes en torno a diversas dudas y problemas suscitados por la obra.

\footnotetext{
${ }^{6}$ Tal es el caso, por ej., de Fernández (2002), no obstante ser una muy buena contribución para comprender las ideas expuestas en dicho opúsculo.

${ }^{7}$ Una original interpretación al respecto, aunque no del todo clara ni mucho menos concluyente, es la del erudito trabajo de Hankey (1992).

${ }^{8}$ No conozco al respecto más que los siguientes: Hankey (1992), Schneider (2003), Tursi (2003) y Cain $(2007,2010)$.
} 
Sin embargo, diversos motivos condujeron a que la ambición heurística de Eschmann no pudiera realizarse de modo satisfactorio. Esto se ve esencialmente en el hecho de que Eschmann haya pasado de considerar el De regno como una obra de circunstancia a una obra de importante calado teórico. Parece cuando menos exagerado pasar de subrayar la carencia de peso doctrinal del De regno, postulando como inadecuado pensar que toda otra doctrina política debe ajustarse a la suya, a considerar que la exposición presente en esa obra contradice decididamente toda otra doctrina política de Tomás de Aquino (ESCHMANN, 1958, p. 196). Es indudable que Eschmann (1958, p. 196) temía ya con que se llegara a pensar que "esa era la doctrina de Santo Tomás al escribir esta obra [i.e., el De regno]"; y parece haberse encandilado de tal forma con la amenaza de absolutizar dicha circunstancia, que, en su determinación de rechazarla enérgicamente, terminó paradójicamente realzándola. Hoy día es más factible vislumbrar que la doctrina del De regno no se presenta realmente de forma tan unilateral y absoluta como él creía.

Detengámonos brevemente en examinar la interpretación de Eschmann al respecto. "En las obras de Santo Tomás de Aquino" - declara Eschmann (1958, p. 177) - " [...] hay dos textos principales que conciernen a las relaciones entre los dos poderes, el «espiritual» y el «temporal», con especial referencia al Papa y su lugar en la Cristiandad”. Esos dos textos son Super II Sent., d. 44, expos. textus, ad 49 (de ahora en más señalado como ' $S$ ') y De regno, II, 3, lin. $110-119^{10}$ (de ahora en más 'R'). "Estos textos” - continúa Eschmann (1958, p.

\footnotetext{
9 "Potestas spiritualis et saecularis utraque deducitur a potestate divina; et ideo intantum saecularis potestas est sub spirituali, inquantum est ei a Deo supposita, scilicet in his quae ad salutem animae pertinent; et ideo in his magis est obediendum potestati spirituali quam saeculari. In his autem quae ad bonum civile pertinent est magis obediendum potestati saeculari quam spirituali, secundum illud Matth. XXII, 21: Reddite quae sunt Caesaris Caesari. Nisi forte potestati spirituali etiam saecularis potestas conjungatur, sicut in papa, qui utriusque potestatis apicem tenet, scilicet spiritualis et saecularis, hoc illo disponente qui est sacerdos et rex, sacerdos in aeternum, secundum ordinem Melchisedech, Rex regum, et Dominus dominantium, cujus potestas non auferetur et regnum non corrumpetur in saecula saeculorum. Amen." (THOMAS DE AQUINO, 1929, p. 1135-1136).

10 "Huiusmodi ergo regni ministerium, ut a terrenis spiritualia essent discreta, non terrenis regibus sed sacerdotibus est commissum, et precipue summo sacerdoti successori Petri, Christi uicario Romano Pontifici, cui omnes reges populi Christiani oportet esse subiectos sicut ipsi domino Ihesu Christo. Sic enim, ut dictum est, ei ad quem ultimi finis pertinet cura subdi debent illi ad quos pertinet cura antecedentium finium, et eius imperio dirigi" (THOMAS DE AQUINO, 1979, p. 466). En realidad no es este el único pasaje del De regno donde se expone esta enseñanza. La comprensión de la misma puede ser completada con la lectura de otros pasajes, sobre todo De regno, II, c.3 y c.4. Cfr., por ej., De regno, II, c.4, lin. 10-14: "[...] manifestum ex dictis fit quod rex, sicut diuino regimine quod administratur per sacerdotum officium subdi debet, ita preesse debet omnibus humanis officiis et ea imperio sui regiminis ordinare". La consecuencia que saca a continuación de ello es esta: "Quia igitur uite qua hic in presenti bene uiuimus, finis est beatitudo caelestis, ad regis officium pertinet
} 
177) - “[... no presentan una identidad de pareceres ni una semejanza tal que pudiera ser fácilmente sintetizada. Antes bien, son contradictorios”. ¿En qué residiría esa contradicción? En opinión de Eschmann, S enseña que el poder secular no deriva del poder espiritual, sino que es un imperium tan original como este, originándose ambos igualmente del poder de Dios. En cambio, la enseñanza de $\mathrm{R}$ es que el poder secular está de tal modo subordinado al poder espiritual, que "el poder espiritual incluye el poder secular" (ESCHMANN, 1959, p. 179). Ahora bien, en la oposición de estas dos formas de entender el poder secular, no sólo está en juego la relación Iglesia-Estado, sino también la preferencia, o bien por un régimen mixto, o bien por uno exclusivamente monárquico. En este sentido, siguiendo la lógica expuesta por Eschmann, en el De regno Tomás de Aquino no sólo estaría proponiendo una concepción hierocrática del poder, sino que estaría incluso ligando esa concepción a la postulación de la monarquía absoluta como mejor forma de gobierno civil. En cambio, la defensa de una legítima autonomía por parte del Estado respecto de la Iglesia, realizada por el Aquinate en otras obras, parecería reclamar más bien un régimen que sabe conjugar el carácter monárquico con el aristocrático y el republicano. Dado que Tomás ha optado por este último tipo de régimen en su forma de pensar más madura ${ }^{11}$, ergo él también preferiría de forma concluyente la autonomía plena del poder civil respecto del eclesiástico. Ahora bien ¿existe realmente la traza de un paralelismo tal en el pensamiento del Aquinate? ¿Es cierto que el De regno aboga por una concepción hierocrática en la relación de las dos espadas, tanto como, unilateralmente, por una monarquía absoluta respecto de la espada civil? Si este no fuera el caso, entonces la supremacía del poder espiritual concebida en el De regno no impediría una legítima y natural autonomía por parte de los poderes civiles, así como tampoco la monarquía expuesta allí excluiría la posibilidad de un legítimo régimen republicano ${ }^{12}$. A continuación evaluaremos -bien que de forma sintética- únicamente la

ea ratione bonam uitam multitudinis procurare secundum quod congruit ad celestem beatitudinem consequendam, ut scilicet ea precipiat que ad celestem beatitudinem ducunt, et eorum contraria secundum quod fuerit possibile interdicat" (De regno, II, c.4, lin. 20-27).

${ }^{11}$ Los lugares clásicos a este respecto son S.th., I-II, q.105, a.1 y I-II, q.90, a.4, y Blythe (1986) es la interpretación más sólida sobre el particular de que tengo noticia.

12 "The distinction between king and tyrant is the chief topic of [De regno,] book one [...] and scholars speculate that his assertion that "the government of the kingdom must be so arranged that the opportunity to tyrannize is removed" [On Kingship, bk. I, ch. 6] refers to establishment of a mixed regime on the model of the Summa [I-II, q. 105, a. 1]" (STONER, 2007). Es pertinente notar al respecto que Stoner remite a continuación a una nota de la ed. inglesa del De regno hecha por Eschmann (1979, p. 24, n. 3), en la que se subraya el carácter incompleto de la doctrina del De regno en este punto. De esta forma, mientras que para Stoner el De regno se encontraría en perfecta 
primera de estas cuestiones. En referencia a la segunda cuestión, cabe señalar que, a diferencia de Eschmann, que ve cierta solución de continuidad doctrinal entre el De regno y la Summa theologiae, hay intérpretes que han sido capaces de ver exactamente lo contrario.

Para Eschmann, el pensamiento genuino de Tomás es el expuesto en $S$, no en R. Este último texto sería el causante de conflicto interno en la obra del medieval, instaurando una permanente tensión entre el poder de la Iglesia y el del Estado. Y aunque "tensión" no signifique otra cosa que "potencial conflicto", la invitación al desencadenamiento de este último estaría francamente realizada. Por el contrario, conforme a $S$, ambos poderes - el secular y el espiritual -

[...] son como primeras causas, cada uno autónomo en su propio orden: el poder espiritual en las cosas que pertenecen a la salvación de las almas, y el poder político en las cosas que conciernen al bien civil. Ninguno de estos poderes es poder absoluto; más bien cada uno es limitado por su propia ratio superioritatis, y conforme a ella. No debemos obediencia alguna al poder espiritual en las cosas que pertenecen al César, tanto como no debemos obediencia alguna al poder secular, de colocar este la hoz en la cosecha del otro poder. (ESCHMANN, 1958, p. 178) ${ }^{13}$.

Esta interpretación respecto de $\mathrm{S}$ es del todo cierta y clarificadora. Donde Eschmann a mi juicio se equivoca es en la lectura de R. En efecto, según él, en R se sostendría una suerte de absorción del poder civil del rey en el poder eclesiástico, que en último término pertenece al vicario de Cristo, el Papa. Indaguemos si $\mathrm{R}$ enseña efectivamente eso. Este texto expone que al poder civil le corresponde procurar aquellos fines que anteceden y son necesarios para la búsqueda del fin último. Esos fines intermedios son, en resumidas cuentas, la buena vida conforme a la virtud ético-política. El fin último, que es la fruitio Dei, sólo puede ser procurado por los agentes espirituales, a los que los gobernantes de la tierra deben subordinarse. De esta forma, y Eschmann

consonancia con la doctrina del régimen mixto de la Summa, para Eschmann lo expuesto en el De regno sería insuficiente para equipararlo a la enseñanza de dicha Summa.

${ }^{13}$ Con todo, Eschmann (1959, p. 178) no pierde la ocasión para aclarar que la mutua autonomía propuesta allí no significa en modo alguno mutua indiferencia: “[...] la distinción, sin embargo, entre lo espiritual y lo secular no es una distinción entre cosa y cosa, sino entre forma y forma. No se enseńa [en S] una separación de las dos esferas, sino la distinción formal de competencias y una relativa y mutua subordinación, que permite que la penetración de lo espiritual en lo secular se cumpla de manera ordenada y justa". 
(1959, p. 179) ha sabido tomar debida nota de esta cuestión, la relación propuesta por $\mathrm{R}$ entre el fin propio del poder espiritual y el del poder secular constituye una relación de unicausalidad, esto es, "un ordo per se causarum, un sistema cerrado de causas, en el que la causa segunda depende per se de la primera causa”. ¿Dónde residiría el error de interpretación? En deducir gratuitamente, a partir de esa enseńanza del De regno, que, en consecuencia, los príncipes de la Cristiandad "ciertamente están sujetos "de forma temporal», no sólo espiritual, al Vicario de Cristo como a Cristo Mismo. Sus regna, los cuales, tomados en su conjunto, son la Cristiandad, son parte de la Iglesia" (ESCHMANN, 1959, p. 179) ${ }^{14}$. Más aun, según Eschmann (1959, p. 180), la ausencia de poder político en el poder eclesiástico que presenta $\mathrm{R}$, es sólo aparente, en la medida en que, según este texto, al Papa "[...] le es conferido el poder político supremo en razón de su supremacía espiritual”. En síntesis, para Eschmann (1959, p. 180) la enseñanza de R se resumiría en la siguiente fórmula: "[...] monismo jerárquico", de corte gregoriano; mientras que la fórmula para identificar $S$ sería la de "dualismo gelasiano"15.

¿Es válido deducir sin problema todo esto de R? De ningún modo. En ningún momento Tomás de Aquino sostiene que la Iglesia absorba en sí misma el reino civil, o que el poder del Papa degluta el poder del rey, por más cristianos que sean tal reino y tal rey. No puede pasarse por alto al respecto

\footnotetext{
${ }^{14}$ De esta forma, la discusión acerca del significado del esquema causal empleado en el De regno termina por dirimirse en la determinación acerca del modo en que Tomás valora o no allí todo lo que podría condensarse bajo el rótulo de 'naturalismo': virtud humana, realidad política, poder temporal. Fernández (2002, p. 62-63), por ejemplo, interpreta que el De regno postularía que “[...] la vida virtuosa a la que debe conducir el dirigente es sólo un medio para alcanzar el fin ultimísimo, la contemplación de Dios" (el subrayado es mío). Con todo, las interpretaciones más recientes - la de Wieland, Schneider, Black, Jordan, Miethke y Bertelloni -, de los que el mismo trabajo de Fernández (2002, p. 68-73) da cuenta, tienden a evaluar que el DR, no obstante plantee una subordinación del ámbito natural respecto del sobrenatural, afirma también a la realidad natural como fin-fin intermedio. Así, por ejemplo, contrario a la interpretación de un uso de una teoría de férrea unicausalidad en el $\mathrm{De}$ regno, Schneider (2003, p. 12-14) - el trabajo más reciente de todos los mencionados por Fernández - considera que el DR hace compatible la teoría platónica de unicausalidad con el recurso a una concepción aristotélica, en la que la unidad causal puede implicar subordinación de una causa a otra y no por ello implicar sujeción.

15 "El dualismo gelasiano del c. [canon] 10, D. [distinctio] 96 [canon Duo sunto quippe de la Summa decretorum de Huguccio; basado en la famosa carta del Papa Gelasio (s. V) al Emperador Atanasio, Duo sunt es sin duda una doctrina del tomismo definitivo" (ESCHMANN, 1959, p. 200); afirmación con la que el dominico alemán reafirma la perennidad de la enseńanza de $S$. Para los antecedentes de $S$ en Gelasio, Graciano, y "[...] la tesis dualista de algunos canonistas del s. XII y s. XIII" (ESCHMANN, 1959, p. 183), ver Eschmann (1959, p. 183-190); a su vez, para la impronta hierocrática, clericalista, derivada de Gregorio VII y supuestamente acogida por R (y antes por Hugo de San Víctor y otros autores similares), ver Eschmann (1959, p. 186-187; 191-195).
} 
que al mismo Eschmann le llame la atención que Martin Grabmann haya destacado la defensa realizada por Tomás en el De regno de la independencia jurídica del príncipe y del orden político respecto del orden espiritual y eclesiástico, así como también la independencia de la filosofía respecto de la teología. A Eschmann (1959, p. 180, n. 18) le resulta curioso que Grabmann haya interpretado así la cuestión contra el parecer de "[...] todos los históricos comentadores", incluido Roberto Belarmino, para quien, como «martillo de herejes» que lo apodaban, la supuesta enseńanza hierocrática de R era de lo más ortodoxa, a diferencia de la dudosa enseńanza de S (ESCHMANN, 1959, p. 177). A Eschmann le parece inconcebible que a partir de la exposición del De regno se suponga una independencia jurídica del rey respecto del sacerdote (en último término del Papa), cuando en más de una ocasión ese texto habla de que el sacerdote imperat (manda) al rey (De regno, II, 3, lin. 87-89; lin. 118; II, 4, lin. 10 $)^{16}$. En síntesis, para Eschmann, el De regno propone una reductio ad unum de los diversos imperia al imperium eclesiástico, no sólo en lo que atañe al estricto orden espiritual, esto es, de salvación de las almas, sino también al orden temporal en sus aspectos jurídico y político. Precisamente, el error del De regno consistiría, según él, en involucrar lo espiritual en la realidad política, diluyendo de ese modo el vigor del imperium civil y entreverando indebidamente la dignidad pontificia en el poder terrenal.

Insistamos con la pregunta: ¡†tiene realmente lugar esta confusión en el De regno? Ya el trabajo de Fitzgerald, de temprana data comparado con el resto de los estudios focalizados en el De regno, aducía que el conflicto imaginado por Eschmann entre $S$ y R era sólo aparente ${ }^{17}$. En orden a ello, el estudio de Fitzgerald traía a la luz la interpretación de varios autores que, antes y después del trabajo de Eschmann (1958), habían sido capaces de no ver desavenencia alguna entre los dos textos tomísticos predichos ${ }^{18}$. No es mi intención, sin

\footnotetext{
${ }^{16}$ Eschmann (1959, p. 182) agrega que es en este sentido jurídico que ha de entenderse también el empleo que el De regno hace de los verbos pasivos correlativos al activo imperare, tales como subdi, esse subditum o subjectum, obedire, servire, famulari.

${ }^{17}$ Además de ubicar principalmente a Eschmann como representante de la tesis de la existencia de conflicto entre S y R, Fitzgerald (1979, p. 538, n. 36) también menciona al respecto el parecer de otros importantes medievalistas, como A.J. Carlyle, O. Lottin y J.A. Watt, quienes de un modo u otro se acercarían a la postura de Eschmann. De nuestra parte cabe mencionar también en esta línea a Bertelloni (2010, p. 19, n.2).

${ }^{18}$ Trabajos de esta índole anteriores al de Eschmann (1958), son los de R. Motte, C. Journet, D'Entreves, R. Niebuhr, M. Maccarrone, M.J. Congar, que se encuentran citados en Fitzgerald (1979, p. 538-540); en cuanto a trabajos posteriores, aparecen los de Weisheipl y L. Boyle (FITZGERALD, 1979 , p. 541, donde se remite a ibid., 528, n. 27). También menciona al respecto, aunque de modo aislado, trabajos de Wilks, Grabmann y Ladner (FITZGERALD, 1979, p. 540, n. 45 y 551, n. 64).
} 
embargo, registrar aquí las razones presentes en los análisis comparativos entre el De regno y otras obras del Aquinate, por las cuales pudiera revelarse la coincidencia o discrepancia de fondo que existe entre las enseñanzas de los distintos textos. Antes bien, me gustaría terminar este acápite haciendo hincapié en la virtud del enfoque hermenéutico de Eschmann, el cual, más allá de sus evidentes insuficiencias, considero que sigue siendo oportuno potenciar.

En efecto, la exploración de campos de influencias históricas no debe darse por acabada. Más aún, la senda hermenéutica con mayores virtualidades para lograr hoy día una comprensión fina del De regno, parece residir, ante todo, en saber detectar allí la presencia de distintas tradiciones de pensamiento ${ }^{19}$. Es notable la indiferencia generalizada de los estudios sobre este opúsculo respecto de las fuentes de su pensamiento, las cuales, por lo demás, ya aparecen identificadas en la edición leonina de hace varias décadas atrás. Dejando de lado la Sagrada Escritura y los historiadores, los editores leoninos han sabido mostrar que el texto del De regno remite, aunque no siempre de forma explícita, a (en orden de aparición): Séneca, Macrobio, Aristóteles, Avicena, Isidoro, Cicerón, Agustín, Gregorio Magno, Pedro Lombardo, Vitruvio, Código de Justiniano (Corpus Iuris Civilis). En consecuencia, antes que seguir explorando - via Eschmann - la presencia del llamado agustinismo político, tal vez sería más conveniente explorar allí la presencia del De civitate Dei de Agustín de Hipona. Esto no parece haberse efectuado en ningún caso de manera sistemática. Surcando esa vía, tal vez sea posible obtener un cuadro más adecuado de la postura tomística del De regno, deshaciendo aporías doctrinales ficticias.

Y si a la hora de leer con provecho la obra política de Tomás de Aquino, se precisa refinar la hermenéutica efectuada por Eschmann, formándose, pues, un cuadro más completo de la tradición de pensamiento político que precede e influye en el De regno, también, en orden a sacar mayor rédito de esa lectura, seguramente conviene tener en cuenta las proyecciones - actuales y potenciales - que dicha obra arroja hacia la Modernidad. A continuación mostraré un ejemplo de este tipo de ejercicio hermenéutico, en el cual también saltarán a la vista los méritos y dificultades del caso.

\footnotetext{
${ }^{19}$ Acerca de la situación actual de la hermenéutica en torno a la obra de Tomás de Aquino y la relación de esta con sus fuentes, particularmente en lo tocante a la relación Iglesia-Estado, son útiles algunas apreciaciones de Hankey (1992, p. 119-123).
} 


\section{El PARADIGMA DE LA FUSIÓN NACIÓN/REPÚBLICA}

Como buen historiador de las ideas que era, Walter Ullmann, uno de los estudiosos del pensamiento político medieval de mayor prestigio en el s. $\mathrm{XX}$, sin mostrar demasiada simpatía o antipatía por el pensamiento de Tomás de Aquino, llegó a convertirse en una referencia obligada para comprender el sentido teórico-político de la obra del Aquinate. Tal como refiere Bertelloni (2000, p. 9-10, p. 12-16), “[...] aproximadamente a partir de mediados de los ańos cincuenta, el tema de la influencia aristotélica sobre la teoría política medieval fue retomado con énfasis por el historiador Walter Ullmann y presentado de modo peculiar". Por supuesto, no le faltaron críticos, y los reproches de estos se enfocaron ante todo en la combinación de simplicidad y desmesura de su esquema de alternancia entre los criterios "descendente" y "ascendente" 20 . En efecto, según Ullmann (1971, p. 23-29, 295), en la Edad Media habían existido dos concepciones contrapuestas para explicar la soberanía del poder político, a saber, la "hierocrática", que operaba según un criterio descendente y unicausal, esto es, monárquico e incluso teocrático, y la "populista" (o republicana), que operaba según un criterio ascendente y en cierta manera pluricausal. El agustinismo político, dominante prácticamente en toda la Edad Media, representa la tesis teocrática, al concebir el poder como "derivado o delegado en la forma de un oficio específico concedido por la divinidad" (ULLMANN, 1971, p. 24), en cambio, el aristotelismo medieval, recuperado a partir del s. XIII, representa la tesis republicana, a la que la idea de representación le es esencialmente inherente. Con respecto a cuál de las dos explicaciones pertenece la postura de Santo Tomás, Ullmann sostiene que a la republicana más que a la hierocrática; inclinándose así por una interpretación más aristotelizante que agustinizante de las teorías políticas tomísticas. Ullmann (1971, p. 186-187) hace notar la prevalencia del criterio ascendente en la obra del Aquinate, por la presencia allí de la tesis de que el mejor régimen de gobierno es un regimen politicum et regale, no sólo uno regale ${ }^{21}$.

A mi juicio, no obstante, la hermenéutica de Ullmann sobre Tomás de Aquino es mucho compleja que la del mero intento por dirimir un debate dialéctico entre los dos criterios predichos. Como haré ver a continuación, en

\footnotetext{
${ }^{20}$ Para exponer este acápite dedicado a la interpretación de Ullmann respecto de Tomás de Aquino, citaré las apreciaciones recogidas en Ullmann (1971, p. 245-256 especialmente), que pueden encontrarse expuestas de forma sintética en Ullmann (1999, p. 166-177 especialmente) y complementadas por Ullmann (1975, p. 269-273).

${ }^{21}$ Blythe (1986, p. 549-550) explica de forma clara la distinción entre poder real o regio y poder político en el pensamiento del Aquinate.
} 
la interpretación del austríaco hay un concepto, que si bien no aparece mucho en su obra (y menos todavía en la de Tomás de Aquino), es del todo decisivo para comprenderla. Tal es el concepto de "nación". Las consideraciones que siguen a continuación tienen por objeto aclarar el rol que Ullmann le da al concepto de "nación" en su hermenéutica del pensamiento tomístico.

$\mathrm{Al}$ abordar la recepción de la filosofía aristotélica por parte de Tomás de Aquino, Ullmann señala que el Aquinate es el primer medieval en aplicar el naturalismo aristotélico al campo de las relaciones sociales humanas, de tal modo que llega a ofrecer "lo que correctamente se ha llamado la primera exposición de una teoría del Estado" (ULLMANN, 1971, p. 249). ¿Qué resulta, según Ullmann, de esa aplicación? Hay tres aspectos característicos de esta teoría política, el tercero de los cuales pertenece al concepto de "nación'. En cuanto a los dos primeros, hay que considerar lo siguiente.

En primer lugar, la concepción de que el Estado o república, que ya en Aristóteles es la sociedad humana perfecta, viene a existir

[...] debido a la eficacia de los instintos naturales del hombre [...]. En su comentario sobre la Politica, Tomás labra con claridad envidiable la tesis ascendente del gobierno y del derecho partiendo de la familia a la aldea, a las ciudades y comunidades superiores hasta su culminación en el Estado. (ULLMANN, 1971, p. 249).

De este modo, en la interpretación de Ullmann, ni en Aristóteles, ni en Tomás de Aquino, existiría, no ya un antagonismo entre naturaleza y vida política, sino tampoco siquiera una diferencia específica entre ambos términos: la república sería fundamentalmente la culminación natural del proceso de organización de la naturaleza en el hombre. El Estado, communitas perfectissima, sería producto de la naturaleza humana en tanto guiada por una razón humana que es fiel seguidora de la ley natural. Ahora bien, en tanto que ser natural, el Estado no sería sino producto necesario, en razón de que "[...] en la naturaleza nada queda imperfecto" (ULLMANN, 1971, p. 249). Incluso toda ley positiva estatal sería necesariamente natural: "[...] cualesquiera sean las leyes creadas por el Estado, tienen que derivarse de la ley natural" (ULLMANN, 1971, p. 249).

De este modo, se obtiene, según Ullmann, la primera caracterización del Estado en sentido tomístico: [1] por un omnicomprensivo aspecto natural, el Estado constituye la naturaleza misma en estado humano perfecto, 
en virtud de una génesis inmanente y orgánica de sentido ascendente; algo, ciertamente, muy diferente a una construcción artificialmente pactada. Así, ese corpus politicum et morale que constituye la república "no ha sido ni fundado, ni instituido ni creado: ha surgido en virtud del instinto natural de los hombres para convivir" (ULLMANN, 1971, p. 250). En este sentido, Ullmann interpreta que, en la concepción tomista de sociedad humana, el aspecto libre no se distingue del natural, siendo este último el preponderante y omniabarcativo: "[...] el Estado no tiene ninguna relación con otro elemento que no sea la naturaleza misma. [...] no se origina en ningún pacto humano; no ha sido creado artificialmente." (ULLMANN, 1971,p. 250).

La segunda característica de esta república natural está estrechamente ligada a la primera. Señala, pues, [2] el sentido de la naturaleza como realidad terrena y posible para el hombre, distinguiéndose así de un más bien imposible ámbito sobrenatural. Siendo su fin el bene vivere, que consiste en la "autosuficiencia” e "independencia”, el Estado no debe apelar a una instancia externa o superior, ni por necesidad, ni, por así decir, por curiosidad. Por el contrario, debe permanecer firme en las proporciones de su humanidad. En este punto, siempre según la interpretación de Ullmann, el Estado en sentido tomístico se diferencia de la Iglesia: "[...] ni en sus orígenes ni en sus orígenes ni en su funcionamiento actual tiene nada que ver con el papado o con cualquier otro organismo eclesiástico" (ULLMANN, 1971, p. 250). El carácter de extrañeza entre Estado e Iglesia según Tomás de Aquino se confirmaría para Ullmann en el hecho de que el origen del organismo eclesiástico es convencional o artificial, no natural.

Finalmente, la característica del Estado en sentido tomístico que Ullmann (1971, p. 250) considera “[...] quizá la más importante”, es la de constituir [3] "una asociación humana", es decir, "una realidad viviente [...], con sus propias leyes, fines, propósitos y órganos". Este aspecto señala el sentido de la naturaleza en tanto que realidad concreta, viva y plural, distinguiéndose de una realidad concebida como abstracta, ideal, utópica y única, que no sería sino fruto de la ideología, o conducente a ella. Según Ullmann (1971, p. 250), esta última característica del Estado se condensaría bien en el concepto de nación. Él no se detiene a clarificar que se trata de un concepto todavía no formulado explícitamente en la obra de Tomás, pero de algún modo lo da a entender.

En conclusión, los tres aspectos, [1], [2] y [3], presentes en la concepción tomista del Estado señalan tres facetas distintas del concepto de "naturaleza" en tanto aplicado a la realidad política; pero el más importante de los tres es 
el de república en tanto entendida como nación. En efecto, este es el concepto de máxima relevancia, según Ullmann, para entender lo que es ser natural conforme a la filosofía política aristotélica.

Desde luego, uno esperaría que el concepto de república fuera descartado del dinamismo natural de la realidad social, conforme a que "república" suele concebirse como una realidad artificialmente pactada, es decir, una región de libertad en tanto que contrapuesta al ámbito de la naturaleza. Esta, desde luego, es la forma en que Hannah Arendt (1997, p. 68-99, 113-114) concibe la filosofía republicana griega en general y aristotélica en particular. Pero Ullmann no parece concebir una contraposición tal entre el ámbito político y el social. En este punto, la estrategia interpretativa de Ullmann es la siguiente: primero, ubica la república en la cima del proceso ascendente de organización natural; como si - según el sentido [1] de naturaleza aplicado al Estado - la libertad cívica fuera tan natural como la familiar, y - según el sentido [2] - tan natural como una realidad terrena. Luego - según el sentido [3] -, sustituye el término "república" por el de "nación", identificando el Estado en su estadio más real con esa realidad concreta, viva y particular llamada "nación”. De este modo, Ullmann borra la cuestión contractual del mapa político, con el riesgo, por cierto, de concebir a la república como una especie de gran familia. De este modo, el ámbito de lo moral y político no sería otra cosa que una especie de extensión perfeccionada de la naturaleza humana, conforme a la aplicación de esta a las operaciones concretas que el hombre realiza o debe realizar para ser hombre en sentido pleno.

De acuerdo a esta estrategia hermenéutica, el concepto de "nación" ha sido desplazado desde la acostumbrada concepción como realidad teórica, inmutable, grave y única, fruto de una ideología teorizante - caracterización presente en el nacionalismo naturalista y en el republicanismo libertario que se le opone -, a una concepción de "nación" como realidad contingente, práctica, cambiante y ágil, fruto de una ciencia política cuyo objeto es lo natural en tanto que algo concreto y vivo. Paradójicamente, Ullmann invierte la interpretación común, según la cual la contingencia residiría en el ámbito de la república, y la necesidad en el de la nación, para afirmar que, en Tomás de Aquino (y antes en Aristóteles), lo necesario y natural reside en la república, la cual, en su estadio de culminante de perfección, resultaría metamorfoseada en realidad nacional; realidad, como se dijo ya, caracterizada por la contingencia. De este modo, Ullmann sostiene que la novedad de Tomás en este punto es haber impreso a la ciencia política medieval un carácter aristotélico práctico. 
En efecto, la ciencia política en sentido aristotélico - recuerda Ullmann - es scientia practica, y como tal, su objeto más propio de estudio es la nación o, más bien, las naciones (en sentido plural, pues no existe "la" Nación). Tal modo de concebir la ciencia política se opone, según él, al modo en que lo hacía el agustinismo, como ciencia especulativa, es decir, como una abstracción que lleva a la ideología (ULLMANN, 1971, p. 250-251). Descartados quedan así, pues, los sueños de hallar en el tomismo una apoyatura adecuada para construir una categoría idealizada, utópica, sobrenatural y hasta fantasmagórica de lo nacional, al estilo fascista o nacionalsocialista. Eso, por el contrario, sería para Ullmann algo propio del agustinismo medieval. En cambio, la ciencia política de corte aristotélico es

[...] parte de las humanae scientiae, las cuales «sunt de rebus a hominibus factis", y por lo tanto, "practicae sive operativae secundum imitationem naturae» (I Pol., lect. 1). [...] Este tipo de pensamiento realista es lo que permite que Tomás diga que, a pesar de que el derecho positivo es la expresión del derecho natural, no obstante varía según el tiempo y las condiciones humanas: Lex recte mutari potest propter mutationem conditionum hominum, quibus secundum diversas eorum conditiones diversa expediunt (S.th., I-II, q.95, a. 3 [corrección: se trata de I-II, q.97, a.1]). (ULLMANN, 1971, p. 251).

Ullmann (1971, p. 276, n. 58) apunta en nota que "Justiniano había señalado claramente el camino" al respecto, al expresar en sus Novellae Constitutiones que "[...] el derecho toma en cuenta la varietas humanae naturae" 22 . Por lo demás, resulta irónico que en el último texto citado de Tomás (S.th., I-II, q.97, a.1), este no use a continuación un ejemplo tomado de Justiniano sino precisamente de Agustín de Hipona... Al respecto, forzoso es apuntar que Ullmann no entiende la filosofía genuina de San Agustín, aunque entienda de agustinismo político. Y por ello tampoco entiende la relación del tomismo con el genuino agustinismo, llegando a afirmar, pues, que "la división del intelecto humano en práctico y especulativo no es más que el reflejo de la distinción entre lo natural y lo sobrenatural" (ULLMANN, 1971, p. 251). Es decir, para Ullmann, la inteligencia especulativa y la práctica estarían asociadas

${ }^{22}$ Este texto citado de las Novellae (collatio secunda, Novella Constitut. VII, cap. II) se pregunta dos líneas más adelante: "[...] quid enim erit stabile inter homines, et ita immobile, ut nullam patiatur mutationem: cum omnis noster status sub perpetuo motu consistat?” (CORPUS JURIS CIVILIS ROMANI, 1830, p. 43). 
respectiva y exclusivamente, cada una por su lado, a la realidad sobrenatural y la natural, siéndoles imposible en su acción un cruce de dirección.

Es, por tanto, a partir de ese esquema de asociaciones de los distintos aspectos de lo natural señalados que se construye, según Ullmann, el tomismo político en contraposición al agustinismo -siendo el concepto de "nación" fundamental para entender la diferencia entre ambos. Todo lo contrario de un nacionalismo de tipo naturalista y reaccionario, que establezca la asociación entre nación y ser natural en tanto ser necesario, Ullmann prefiere explorar una supuesta asociación tomista entre nación y ser natural en el sentido de ser contingente ${ }^{23}$. Después de todo, la nación no podría entenderse desde una ley natural, como piensa el naturalismo, sino desde una ley positiva (jus positivum), en la medida en que la nación es la comunidad humana en su concreción contingente, y no en su inmutable idealización o abstracción. Además, al sentido de concreción y contingencia inherente a la nación, le iría adjunto naturalmente el de utilidad. Así, si la ley humana tiene un sentido utilitario, dado que su "[...] fin u objetivo [...] es la utilitas hominum" (ULLMANN, 1971, p. 252), el mismo sentido tendrá también la nación, de la que esa ley emana.

Resulta ciertamente notable cómo se las ingenia Ullmann para cambiar de signo el concepto de "nación" y el "nacionalismo" derivado de aquel: de un naturalismo organicista, determinista, la nación ha pasado a pertenecer a una concepción de la naturaleza de tipo contingentista y pragmatista. Así, en la interpretación de Ullmann, lo natural, que, en cuanto realidad específicamente política, es ser nacional, para Tomás de Aquino significa ser individual, concreto, contingente y útil. La Nación es una ficción; lo que es real son las naciones, que, en un tiempo y espacio geográfico determinados, cuentan con una fundación humana deliberada por medio de un jus positivum, según un legem ponere humano que le da origen. En este sentido, aunque natio o civitas

\footnotetext{
23 "Como las condiciones humanas varían según el lugar y el tiempo, deben variar también las leyes reguladoras de esas condiciones. Por tanto, la ley humana es variable [y con ella también la nación]: no tiene ninguna de las características inmutables que se atribuyen a la ley natural" (ULLMANN, 1971, p. 251). En la interpretación de Ullmann influye una nota histórico-contextual insoslayable, que es la del sentido nacionalsocialista que pesaba sobre el concepto de "nación" en sus ańos de producción intelectual. De hecho, él era un judío que había tenido que exiliarse en Inglaterra. En este sentido, para entender que la hermenéutica de Ullmann no es completamente insólita, puede recordarse aquí la inversión efectuada por otro judío exiliado del régimen nazi, Stefan Zweig, sobre el significado del nacionalismo. Zweig aduce que el supuesto nacionalismo de Nietzsche en realidad es cosmopolitismo (ZWEIG, 1999, cap. 7 "El descubrimiento del Sur"). En pocas palabras, lo que se revela a través de este tipo de autores es que el sentido nacionalsocialista de 'nación' no contaba en absoluto, incluso en aquellos ańos, con la última palabra para explicar la realidad histórica de las cosas.
} 
sean términos que destacan, cada uno, diversos matices, en lo que hace a la indicación de la realidad concreta, da lo mismo decir que se está en presencia de una natio o una civitas. En efecto, "nación" indica la última concreción política específica de un ethos determinado, según este o aquel Estado, y no uno que pretenda representar un relato político único. Ullmann no ve oposición del jus positivum a la lex naturalis, sino su natural continuación: pues aunque la ley natural sea una e inmutable, es, sin embargo, real ${ }^{4}$. En cambio, él sí encuentra oposición entre el jus positivum y el supuesto carácter abstracto e ideal de las leyes eclesiásticas y sobrenaturales, cuyas pretensiones de validez universal las habrían hecho irreales por irrealizables. Así, si las naciones son inexorablemente muchas, en cambio, la Iglesia medieval pretende ser una sola. De ahí su fracaso -infiere Ullmann- para realizarse políticamente. Ahora bien, tal como juzga Ullmann (1971, p. 252) (esta vez con razón), dicho fracaso no podía ser para Tomás de Aquino motivo de intranquilidad, considerando que "[...] cada vez se veía más a la Iglesia como el corpus mysticum" que podía armonizar con el corpus politicum et morale.

En conclusión, según Ullmann, en Tomás pesaría finalmente más el concepto de "nación" que el de "república". Y ello sin perder de vista que en este autor medieval dicho concepto estaría todavía en ciernes, esto es, en estado de formación. Con todo, conforme a Ullmann, de la obra de Tomás ya podría deducirse que "nación" es lo social natural en su estadio último de perfección o concreción: si el hombre, para perfeccionarse, necesita de la vida en sociedad, "nación" no indica la culminación o perfección de la naturaleza humana in abstracto, sino la comunidad humana concreta, conforme a un tiempo y lugar determinados, según la promulgación de tales o cuales leyes. Ullmann ve que hacia el s. XIII, y particularmente con Tomás de Aquino, comienza a darse una “[...] creciente importancia teórica y práctica del concepto de natio, en tanto

\footnotetext{
${ }^{24}$ Ullmann (1971, p 276, n. 60) remite en nota a S.th., I-II, q.95, a.2, ad 3, donde se señala que "[...] la diversidad de la ley positiva" se debe a la gran variedad "[...] de las realidades humanas". Ahora bien, por la doctrina del mismo texto se ve que dicha diversidad y contingencia no va reńida con la unidad y necesidad de la ley natural, que es de algún modo común a todas las variaciones positivas. Y para confirmar esta armonía, en la misma nota Ullmann seńala que "[... la inmutabilidad de la ley natural, así como la mutabilidad del derecho positivo, fueron seńaladas por Justiniano en sus Inst., I, ii, 1". De hecho, el texto citado de Tomás remite claramente al de Justiniano. En efecto, el texto romano de las Institutiones (liber I, tit. II, $\$ 1$ ) se expresa así: “[...] omnes populi, qui legibus et moribus reguntur, partim suo proprio, partim communi omnium hominum jure utuntur. Nam quod quisque populus ipse sibi jus constituit, id ipsius proprium civitatis est" (CORPUS JURIS CIVILIS ROMANI, 1928, p. 3); y el de Tomás se hace eco de la siguiente manera: “[...] principia communia legis naturae non possunt eodem modo applicari omnibus, propter multam varietatem rerum humanarum. Et exinde provenit diversitas legis positivae apud diversos". (S.th., I-II, q.95, a.2, ad 3).
} 
entidad que establecía una civilitas originalis para sus miembros" (ULLMANN, 1971, p. 295). "Civilidad original" no significa otra cosa que vida civilizada particular, ethos concreto en cada uno de los miembros de una determinada sociedad. De ahí se explicaría, para Ullmann (1971, p. 294-295), el declive de las ciencias jurídicas cultivadas en las universidades, carentes de valor práctico, y el auge del derecho nacional, esto es, el estudio y promulgación de leyes de cada reino de forma autónoma.

En consecuencia, la virtud de la hermenéutica de Ullmann reside en haber sabido identificar la importancia del concepto de "nación" en la obra de Tomás de Aquino, incluso aunque el mismo no tenga allí prácticamente apariencia textual. Sin embargo, al igual que procedíamos en la valoración de la interpretación de Eschmann, cabe preguntarse si la exposición de Ullmann condice o no con el pensamiento genuino de Tomás de Aquino en torno a la relación república/nación. Y así como respecto del De regno juzgábamos provechoso seguir explorando las raíces profundas de la vía tomista de cooperación entre Iglesia y Estado (a diferencia de Eschmann, que supone una tensión entre ambas instituciones), por su parte, respecto de la interpretación de Ullmann, al tiempo de cuestionar esa supuesta fusión entre "república" y "nación” en el pensamiento del Aquinate, tal vez haya todavía mucho que indagar sobre las consecuencias que pudieran desprenderse de dichos conceptos siguiendo aspectos desconocidos de su lógica.

ARGÜELLO, Santiago. Two paradigmatic hermeneutics of the political thought of Thomas Aquinas: their virtues, limitations, and potentialities. Trans/form/ação, Marília, v. 39, n. 2, p. 31-52, Abr./Jun., 2016.

\begin{abstract}
The present paper deals with two of the main 20th Century hermeneutic models that explain the political thought of Thomas Aquinas. One, well represented by the work of I. Th. Eschmann, regards the relation between Aquinas and his predecessors. The other, well represented by W. Ullmann, looks at the relation between Aquinas and modern thought. In demarcating the virtues as well the limitations of these two hermeneutic models, it is possible to understand the potentialities present in them and to discover new ways for overcoming, on the one hand, the imagined strain between the power of ecclesiastical and the civil authorities, and, on the other hand, fears regarding the concept of nation. This last concept, although embryonic in Aquinas' works, is essential to not misunderstanding his Aristotelian republicanism.
\end{abstract}

KEYWORDS: Thomas Aquinas, medieval political thought, church, state, nation. 


\section{REFERENCIAS}

ARENDT, H. Qué es política. Tradução de R. Sala Carbó. Barcelona: Paidós, 1997. [Was ist politik? Aus dem Nachlaß, 1993].

. La condición humana. Tradução de R. Gil Novales. Buenos Aires; Barcelona; México: Paidós, 2003. [The Human condition, 1958].

BERTELLONI, F. Una resignificación protomoderna del Estado (= regnum) en el tratado De potestate regia et papali de Juan Quidort de París. Scripta mediaevalia, v. 2, n.2, p. 5583, 2009 .

. La teoría política medieval entre la tradición clásica y la modernidad. In: ROCHE ARNAS, P. (Coord.). El pensamiento político en la Edad Media. Madrid: Centro de Estudios Ramón Areces, 2010. p. 17-40.

BLYTHE, J. M. The mixed constitution and the distinction between regal and political power in the work of Thomas Aquinas. Journal of the History of Ideas, v. 47, n. 4, p. 547$565,1986$.

CAIN, P. Thomas Aquinas' De Regno: political philosophy, theocracy, and esoteric writing. In: CANADIAN POLITICAL SCIENCE ASSOCIATION ANNUAL CONFERENCE, 2007. Disponível em: <https://www.cpsa-acsp.ca/papers-2007/Cain.pdf>. Acesso em: 15 abr. 2016.

. Thomas Aquinas' De Regno: Political Philosophy and the City of God: The Best Regime in Thomas Aquinas' On Kingship. In: THE ANNUAL MEETING OF THE SOUTHERN POLITICAL SCIENCE ASSOCIATION, Crowne Plaza Hotel Ravinia, Atlanta, Georgia, Jan 06, 2010. Disponível em: <http://citation.allacademic.com//meta/p_ mla_apa_research_citation/3/9/6/5/8/pages396582/p396582-1.php>. Acesso em: 15 abr. 2016.

CORPUS JURIS CIVILIS ROMANI. Institutionum seu elementorum D. Justiniani. Editado por Dionysius Gothofredus et al. Neapoli: Januarium Mirelli Bibliopolam, t. I, 1828. Disponível em: <http://www.archive.org/stream/corpusiuriscivil01gode\#page/3/ mode/1up>. Acesso em: 15 abr.2016.

. Authenticae, seu novellae constitutiones Dn. Justiniani [etc.]. Editado por Dionysius Gothofredus et al. Neapoli: Januarium Mirelli Bibliopolam, t. V, 1830. Disponível em: $<$ http://www.archive.org/stream/corpusiuriscivil05gode\#page/42/mode/2up >. Acesso em: 15 abr. 2016.

DONDAINE, H.-F. Préface. In: De regno ad regem Cypri. In: Sancti Thomae de Aquino Opera Omnia, tomus XLII. Roma: Iussu Leonis XIII P. M. edita, cura et studio fratrum praedicatorum, Editori di San Tommaso, 1979. p. 419-446.

ESCHMANN, I. Th. Studies on the notion of society in St. Thomas Aquinas. I. St. Thomas and the Decretal of Innocent IV Romana Ecclesia: Ceterum, Mediaeval Studies, v. 8 , p. 1-42, 1946. 
Studies on the notion of society in St. Thomas Aquinas. II. Thomistic social philosophy and the theology of original Sin. Mediaeval Studies, v. 9, p. 19-55, 1947.

. The quotations of Aristotle's politics in St. Thomas' Lectura super Matthaeum. Mediaeval Studies, v. 19, p. 232-240, 1956.

1958.

St. Thomas Aquinas on the two powers. Mediaeval Studies, v. 20, p. 177-205,

Introduction. In: ST. THOMAS AQUINAS. On Kingship to the King of Cyprus. Tradução de G.B. Phelan (under the title On the Governance of Rulers) revised with introduction and notes by I.T. Eschmann. Reimpresión de la ed. de 1949 editada por el Pontifical Institute of Mediaeval Studies, Toronto Westport. Connecticut: Hyperion, 1979.

FERNÁNDEZ, C. J. Origen y finalidad de la política en el De regno de Tomás de Aquino. Mediaevalia, v. 21, p. 57-87, 2002.

FITZGERALD, L.P. Saint Thomas Aquinas and the two powers. Angelicum, v. 56, p. 515$556,1979$.

HABERMAS, J. Teoría y praxis. Estudios de filosofía social. Tradução de S. Mas Torres y C. Moya Espí. Madrid: Tecnos, 1987. (Theorie und Praxis, 1963).

HANKEY, W. J. Dionysius dixit, Lex divinitatis est ultima per media reducere. Aquinas, Hierocracy and the 'augustinisme politique'. Medioevo: Rivista di Storia della Filosofia Medievale, Editado por Ilario Tolomio, v. 18, p. 119-150, 1992. (Tommaso D’Aquino: proposte nuove di letture" (Festschrift Antonio Tognolo).

IMBACH, R. Démocratie ou monarchie? La discussion sur le meilleur régime politique chez quelques interprèts français de Thomas d'Aquin (1893-1928). In: BONINO, S. Th. (Ed.), Saint Thomas au XXe siècle: colloque du centenaire de la "Revue thomiste», Toulouse, 25-28 mars 1993. Paris: Éditions Saint Paul, 1994. p. 335-350.

SCHNEIDER, J. H.J. La filosofía política en el De regno de Tomás de Aquino.Tradução de G. D. Corbi. Patristica et Medievalia, v. 24, p. 3-27, 2003.

STONER, J. Was Thomas Aquinas a Republican? In: THE ANNUAL MEETING OF THE SOUTHERN POLITICAL SCIENCE ASSOCIATION, Hotel InterContinental, New Orleans, LA, Jan 03, 2007. Disponível em: <http://citation.allacademic.com/meta/p_ mla_apa_research_citation/1/4/3/3/7/p143379_index.html>. Acesso el: 15 abr. 2016.

THOMAS DE AQUINO. Scriptum super libros Sententiarum magistri Petri Lombardi episcopi Parisiensis, t. 2 [Super II Sent.], Editado por P. Mandonnet). Paris: P. Lethielleux, 1929.

De regno ad regem Cypri [De regno]. In: Sancti Thomae de Aquino Opera Omnia, t. 42. Roma: Iussu Leonis XIII P. M. edita, cura et studio fratrum praedicatorum, Editori di San Tommaso, 1979. p. 447-471.

TURSI, A. D. Introducción. In: TOMÁS DE AQUINO, Del ente y de la esencia. del reino Tradução de L. Wagner de Reina y A.D. Tursi. Buenos Aires: Losada, 2003. p. 51-58. 
ULLMANN, W. Principios de gobierno y teoría politica en la Edad Media. Tradução de Graciela Soriano. Madrid: Revista de Occidente, 1971. (Principles of Government and Politics in the Middle Ages, 1961).

Law and Politics in the Middle Ages: an introduction to the sources of medieval political ideas. Cambridge; New York: Cambridge University Press, 1975.

Historia del pensamiento político en la Edad Media. Tradução de R. Vilaró Piñol. Barcelona: Ariel, 1999. (A History of Political Thought: The Middle Ages, 1965).

ZWEIG, S. La lucha contra el demonio. Hölderlin, Kleist, Nietzsche. Tradução de Joaquín Verdaguer. Madrid: Acantilado, 1999. (Der Kampf mit dem Dämon. Hölderlin - KleistNietzsche, 1925).

Recebido em 23/11/2015

Aceito em 17/01/2016 
ARGÜELLO, S. 